\title{
A tale of two countries: environmental impacts on social participation after spinal cord injury
}

\author{
MPJM Dijkers*,1, G Yavuzer $^{2}$, S Ergin ${ }^{2}$, D Weitzenkamp ${ }^{3}$ and GG Whiteneck ${ }^{3}$ \\ ${ }^{1}$ Department of Rehabilitation Medicine, Mount Sinai School of Medicine, New York, NY, USA; ${ }^{2}$ Department of \\ Physical Medicine and Rehabilitation, Ankara University, Ankara, Turkey; ${ }^{3}$ Department of Research, Craig Hospital, \\ Englewood, CO, USA
}

\begin{abstract}
Study design: Comparative analysis of survey data produced in two countries. Objectives: To assess the degree to which environmental barriers impact social participation, and to identify the aspects of participation most affected.

Setting: Community-dwelling individuals with spinal cord injury in the USA and Turkey. Methods: Subjects completed the Functional Independence Measure (FIM) motor score, the Craig Hospital Inventory of Environmental Factors (CHIEF), and the Craig Handicap Assessment and Reporting Technique (CHART). Analysis of co-variance was used to analyze CHIEF and CHART differences within and between country.

Results: US subjects reported higher participation scores (CHART) and lower barriers (CHIEF), however, when controls for age, gender, time since injury and motor ability (FIM) were applied, country differences in reports of barriers were limited. Motor ability was the major predictor of participation, which was minimally affected by barriers.

Conclusion: Conceptualization and measurement issues may have been the reason for the minimal support for the hypothesis that environment affects participation. Suggestions for future research are made.

Sponsorship: National Institute on Disability and Rehabilitation Research, Centers for Disease Control and Prevention.

Spinal Cord (2002) 40, 351-362. doi:10.1038/sj.sc.3101310
\end{abstract}

Keywords: spinal cord injury; architectural accessibility; activities of daily living; outcome assessment (health care); rehabilitation; disabled persons

\section{Introduction}

The World Health Organization Model of disablement, which underlies the new International Classification of Functioning, ${ }^{1}$ the Quebec model $^{2}$ and the 'new paradigm' of the National Institute on Disability and Rehabilitation Research, ${ }^{3}$ all hold that the functioning of people with impairments is affected by the environment in which they operate, as much as by their specific anatomical and physiological deficits. That is to say, impairment and the environment act together and interact to affect quality and quantity of common task fulfillment (Activities of Daily Living ADLs). Further, impairment, ADLs and mobility interact with the social, cultural and physical environment to impact social participation. With 'social participation' we refer to the satisfaction of needs

*Correspondence: MPJM Dijkers, Dept. of Rehabilitation Medicine, Box 1240, Mount Sinai School of Medicine, One Gustave Levy Place, New York, NY 10029-6574, USA and the accomplishment of personal, professional and public goals in direct and indirect contact with others, in one's immediate family and neighbourhood, and in society at large. ${ }^{4}$

These models reflect a common-sense understanding, but common sense is not always reflected in the activities of rehabilitation professions and organizations. As health professionals, rehabilitation practitioners often have been trained in an individualistic approach to curing diseases. This often results in treatments that focus on the individual and his or her deficits, rather than on the environment and the barriers and supports for functioning that it offers. In order to improve rehabilitation services, we need to develop and test the models of the social and environmental origin of disability.

One way of testing the models is to compare specific environments with one another. This can be done at the micro-level, e.g. evaluating performance of hygiene 
tasks by a single group of persons with impairments in bathrooms of various layouts. ${ }^{5}$ Testing meso- and macro-levels of the cultural and social environment is not as easy, as large-scale social experiments are extremely costly and difficult to implement. Instead, selected aspects of the models could be tested by comparing past and present within one society that has seen major changes in barriers and supports for people with disabilities. For instance, one could compare social participation by persons with a specific impairment between the early 2000s and the early 1950s. However, in the absence of sophisticated measures of participation in the 1950s, comparisons would be limited to simple indicators, such as contrasting the percentage working or attending school.

Another approach is to compare sectors or areas within a society that differ in barriers. Since legal, social and cultural influences are likely to operate society-wide, such a comparison would necessarily focus on the physical barriers, such as those between newly built suburbs and older cities that have not seen much modification. A more feasible alternative is to compare societies with sizable differences in barriers and supports, using data newly collected for both. This paper offers a comparison of social participation of persons with a spinal cord injury (SCI) between Turkey and the United States.

Turkey is a country of 65.6 million people (2000 estimate) that straddles Europe and Asia. It is a multiparty democracy created from the remains of the Ottoman empire by Ataturk, who in the 1920s and 1930s set the country on a course of secularization, westernization and modernization. The population is fairly homogeneous. Turkish is the official language, and Islam the religion of the overwhelming majority, although it is not a state religion. Both its population and its economy are growing fast. The population growth rate of $1.6 \%$ per year for the $1990-2000$ period results in a population that is very young: $29 \%$ under 15 years of age and only $6 \% 65$ or older. The economy, which still has a significant agricultural component (over $50 \%$ of the population engaged in 'primary sector' occupations per the 1990 census) is moving fast into manufacturing $(12 \%)$ and services $(17 \%)$, wholesale and retail $(8 \%)$, transportation and communication (4\%). The annual growth rate of the economy in the 1987-1993 period was $4.4 \%$ on average. In the larger cities, it is easy to imagine oneself in a western metropolis; however, the countryside is still traditional, with small farm holdings and animal power supplementing mechanized farm equipment.

The United States of America has a population of 281 million (2000 estimate), which is fairly heterogeneous in terms of race/ethnic group, religion, and even language - over $10 \%$ speak a language other than English at home. The birth rate is low (14.5 per 1000 in 2000), and population growth is partly the result of immigration: $9.5 \%$ of the population is foreign-born. The populace is aging; in 2000, $12.7 \%$ was 65 or older. The country is very urbanized, with $80.3 \%$ living in metropolitan areas. Only $2.5 \%$ of the civil labor force is engaged in agriculture, and less than $20 \%$ in manufacturing and other goods production. Almost two-thirds $(64.8 \%)$ is employed in various service industries. The economy was in a growth cycle throughout the $1990 \mathrm{~s}$, with an average growth rate of $5.3 \%$ per year. The USA has a 'mature' two party democracy. The cultural values reflected in its institutions are predominantly Western European Judeo-Christian, although this is changing with the continuing influx of groups from other backgrounds.

An USA-Turkey comparison of environmental barriers and supports for community participation of persons with a disability (with a focus on individuals with SCI) is provided in Table 1. This is an overview painted with broad brush strokes based on the authors' familiarity with the two societies. Each row in this table could be annotated with extensive footnotes giving detail, results of limited empirical studies, and support for generalizations somewhat at odds with the ones given here. However, these differences form the basis for our hypotheses regarding the dissimilarity between the two societies in environmental barriers and social participation of persons with SCI:

(1) Barriers (except for those posed by the natural environment) are higher in Turkey, and supports lower (except for within-family supports), than in the USA.

(2) Social participation is higher in the USA, specifically in the areas of mobility and occupation, for persons with similar levels of impairment and basic motor ability.

(3) A major reason for lower levels of participation in Turkey are greater attitudinal, physical and program/policy barriers, and lower levels of services, as experienced by persons with SCI. Physical access and problems created by programs and policies outside the home environment are especially problematic. Therefore, any differences in social participation between Turkey and the USA will be reduced or eliminated after controlling for reported frequency and significance of barriers.

The measures used in this comparison, the CHART (Craig Handicap Assessment and Reporting Technique) and CHIEF (Craig Hospital Inventory of Environmental Factors), described below, offer quantifications of a number of aspects of the social participation of persons with a disability, and the environment in which they function, respectively. However, they can hardly be claimed to offer comprehensive assessments of their target concepts. For this and other reasons, this should be considered a pilot study, with the primary aim of exploring to what degree participation differences between persons with SCI in different societies can be linked to societal 
Table 1 Summary of barriers and supports for social participation of persons with a disability

Domain USA Turkey

Cultural depictions and public attitudes toward persons with a disability

Civil and other rights laws

Income support provisions

Health care coverage

Coverage of wheelchairs, other equipment, supplies

Housing

Accessibility of public spaces and buildings

Accessibility of public transportation

Accessibility of private businesses and organizations (malls, sports facilities, etc.)

Accessibility of private residences

Government programs federal and state level

Government programs local level
Unease in many interactions; assumption of spread of specific disability to all aspects of the person's functioning; no support for denigration or discrimination, but subtle and not-so-subtle incidences of both. Still much stereotyping as well as invisibility in media, but increasing instances of depiction of disability as just another human characteristic

Laws in place to guarantee civil rights: right to least-restrictive setting, schooling, employment, health care; enforcement is variable

Supplemental Security Income (SSI) and Social Security Disability Income (SSDI) programs offer lifelong income for those with a work disability

Medicaid and Medicare offer minimum health and rehabilitative services for those without private insurance or other coverage

Basics are covered in all situations; availability of advanced items, repairs and replacements depend on health care coverage

Institutional care almost completely abolished; persons with disability live in private residences or communityintegrated small group homes All newer buildings and many older ones accessible; curb cuts and handicapped parking almost universal

Americans with Disabilities Act (AA), requires access; almost all buses equipped with lifts, but actual availability and use is variable; trains, planes accessible but with difficulty and require preplanning; dial-aride widely available but generally poor All newer buildings and many older ones accessible, although often only at most basic level; ADA requires access and job accommodation

Very limited number of fully accessible apartments available; renovation of existing housing is an individual responsibility for which many have no funds

Support for vocational rehabilitation and independent living programs, accessible housing, recreation programs

Recreation programs for persons with a disability; some outdoors recreation facilities accessible; special services and support programs in many school districts and universities and colleges; supported workshops and other programs of employment
Disability is considered to be sent by God. The person with a disability is treated like a baby and should be taken care of, fed, cleaned. If the parent or spouse does not provide this care, they disgrace themselves, and people in their social circle will criticize them

Laws are on the books, but civil organizations lack the power to impose rule enforcement, or it is cheaper for the violators to pay the penalty rather than to obey the laws

People with a disability are entitled to a life long pension, but the amount is not enough to live on, at least in the big cities

All health and rehabilitative services are covered by insurance, but not everybody has insurance

Standard wheelchairs, orthoses and walking aids are covered under insurance, but not powered wheelchairs

There are no nursing homes, and a very limited number of accessible private residences. Persons with a disability are expected to live with their family Very few buildings are accessible, only the newer ones in the big cities. School buildings by law should provide access according to the needs of the students, but because of economical problems this is not implemented

In some cities, there are accessible buses on very limited routes and just for twice a day. No other special transportation than ambulances exists

Even in Ankara, the capital, there is only one cinema that is accessible. There are handicap parking spaces in some shopping malls in the big cities, but they are always occupied by non-handicapped persons Laws specify that apartment buildings should change access according to the needs of the renters, but because of economical problems it is not done

The government provides support for vocational rehabilitation programs

Regional recreation programs once or twice a year 
Table 1 continued

\begin{tabular}{lll}
\hline Domain & USA & Turkey \\
\hline Private programs & $\begin{array}{l}\text { Support, communication, education, } \\
\text { recreation programs by a wide array of } \\
\text { voluntary organizations of and for } \\
\text { persons with a disability }\end{array}$ & $\begin{array}{l}\text { Very limited number and range of } \\
\text { voluntary organizations, only one } \\
\text { organization for people with SCI }\end{array}$ \\
\hline
\end{tabular}

features, specifically barriers to and resources for functioning.

\section{Methods}

The Turkish sample consists of individuals with traumatic SCI being followed by the rehabilitation service of the Cebeci Hospital affiliated with Ankara University. It is a convenience sample of persons attending clinic for routine follow-up or for specific problems. A total of 66 patients agreed to take part in the study; an estimated 25 were not invited or refused participation because of lack of time or other reasons. A questionnaire incorporating CHART, CHIEF, and the Functional Independence Measure (FIM) was administered by the second author. Additional data (age, time since injury, level and completeness of injury) were abstracted from medical records.

The USA sample consists of participants eligible for National Spinal Cord Injury Database (NSCIDB) follow-up during the calendar year 2000 at Craig Hospital in Englewood (CO, USA). Those enrolled by Craig Hospital in the NSCIDB all incurred a spinal cord injury in the states of Colorado or Wyoming and entered the system of care within 60 days of injury. In addition to an extensive data collection during the initial hospitalization (NSCIDB Form I), individuals who give their consent are also interviewed to complete the NSCIDB Form II upon reaching their first, second, or fifth year anniversary post SCI and every 5 years after that. During their follow-up, 130 people were asked about their environmental barriers using the CHIEF (described below). Additional information similar to that available for the Turkish sample (including FIM and CHART) was abstracted from current or prior NSCIDB Forms I or II.

The Craig Handicap Assessment and Reporting Technique (CHART) ${ }^{6}$ was modeled directly on the World Health Organization's handicap dimensions (ICIDH-1, first published in 1980). There is quite adequate evidence for reliability and validity of the CHART ${ }^{6-8}$ and the instrument is increasingly used with populations other than those with SCI. ${ }^{9}$ The CHART-Short Form used here consists of 20 questions, which are combined to provide subscale scores for the six dimensions (Social Integration, Mobility, Occupation, Physical Independence, Cognitive Independence, Economic Self-sufficiency). The CHART scoring algorithm was developed such that the typical non-disabled person scores 100 on each dimension, while the person with maximal handicap scores 0 . Because this creates extremely skewed score distributions, for some tabulations (involving Mobility, Social Integration and Occupation) we also used modified algorithms that do not cap the maximum score. ${ }^{10}$

The CHART Economic Self-sufficiency scores were not analyzed due to the incomparability of poverty levels between the two countries (CHART Economic Self-sufficiency categories are tagged to official US poverty levels) and the recent hyper-inflation in Turkey which affects Lira-Dollar exchange rates. The CHART Cognitive Independence scores were also dropped from analysis due to lack of variability: all Turkish subjects and almost all US ones had maximum scores. Cognitive Independence and Economic Self-sufficiency are also not part of the CHART-SF total score used here, which is based on subscale totals in their 'uncapped' version.

The Craig Hospital Inventory of Environmental Factors (CHIEF) is one of the few instruments to quantify the environment as it affects functioning of people with a disability. ${ }^{11}$ The approach taken in developing the CHIEF was to identify major dimensions of the environment that may impede or facilitate participation by people with disability: accessibility, accommodation, resource availability, social support, and equality. Extensive panel meetings and pilot testing yielded the 12-item CHIEF-Short Form used here. It should be noted that the CHIEF does not measure environments and their characteristics objectively, but elicits a characterization of the severity of perceived barriers to social participation, as reported by individuals with a disability. Three scores are obtained for each item: (1) a score on a scale of $0-4$ indicating the frequency with which barriers are encountered; (2) a magnitude score on a scale of $0-$ 2 indicating the extent of the problem a barrier typically presents; and (3) a frequency by magnitude product score on a scale of $0-8$, indicating the overall impact of the barrier. Summary scores for subscales and total scores are taken as the average of item scores. Psychometric properties were evaluated using a convenience sample of 409 individuals with disability, including 124 participants with SCI. Test-retest reliability was evaluated using the intraclass correlation coefficient (ICC), which was highest for the product scores. In the SCI sample, subscale ICC values for product scores ranged from 0.67-0.91, 
while that of the total scale was $0.91 .^{11}$ The product scores are used in the present analysis.

A large percentage of the US and Turkish subjects stated that the questions on barriers in work or school were not applicable to them. Three solutions are open in a situation like this: calculating their score based on the remaining items only (with or without adjustment for the different maximum score possible); calculating a total score with assignment of a score of 0 (no barriers); assigning a missing value code, and omitting these cases from the analysis altogether. The first approach is not feasible for subscores that only have 'not applicable' items such as the CHIEF Work/ School scale. The latter two have potentially very much different impact on findings (see Discussion); therefore, we report the relevant analyses in two ways: elimination of this subgroup, and assuming that they meant 'no barrier'.

The Functional Independence Measure (FIM) is an 18 item assessment that evaluates a patient's independence in activities of daily living. ${ }^{12}$ The instrument has gone through extensive trials, has been tested for reliability in SCI and other impairment groups ${ }^{13,14}$ and incorporated into the NSCIDB and the NASCIS III trial. ${ }^{15}$ The FIM contains two distinct subscales, a 13item motor subscale used in this study, and a 5-item cognitive subscale. ${ }^{16}$ Recent studies have confirmed the high reliability of the motor FIM across many impairment groups, including SCI. ${ }^{14}$ Two recent analyses showed the reliability of the self-reported Motor FIM in SCI follow-up. . $^{17,18}$

Both the CHART and the CHIEF were translated into Turkish using a back translation procedure. The second author, who has familiarity with English through a stay in the USA, translated from English to Turkish. A second physician with similar experience translated back into English, after which the two met to discuss any discrepancies. The Turkish translation of the FIM, performed by the second author and colleagues, has been shown to produce reliable and valid data. ${ }^{19}$

Data analysis involved calculating descriptive summaries such as means and frequencies for outcome and predictor variables, and analyzing differences between countries, using analysis of co-variance for continuous variables and chi-square for categorical variables. The US and Turkish participants differed in a number of aspects relevant to experience of barriers and social participation, including age, level of injury and motor ability. We used analysis of co-variance to eliminate these differences statistically, and achieve a 'better' comparison between countries. Finally, predictive models were developed to test whether differences between the two countries in community participation (as measured by CHART) could be accounted for by differences in environmental factors. For each subscore of CHART, two models were tested using analysis of co-variance: one without CHIEF scores and one with these scores. Both models included the predictors of country, gender, time since onset, and motor FIM scores. Two-way interactions of country with each other predictor were included to account for the possibility of differences in the predictor/outcome relationship between countries. Eta-squared was used to report the proportion of variance that a single predictor explains, controlling for the effect of all other predictors. R-squared was used to quantify the proportion of variance accounted for by the entire model. Comparisons of the model with and without CHIEF were made to assess the role of environmental factors in levels of participation.

\section{Results}

The Turkish subjects more often are female, and typically have an injury at the low thoracic or lumbar/sacral level (Table 2). The latter is the result of mortality patterns: in Turkey, persons with higher levels of injury are less likely to survive because of limitations in medical expertise and resources. The Turkish subjects were on average 3 years post injury, versus 16 for the US sample (Table 2); this 13 year difference is consistent with the difference in current age between the samples. In spite of lower levels of injury, the Turkish subjects spent almost twice as many days in inpatient rehabilitation. This reflects health care organization and delivery patterns as much as rehabilitative needs or expertise. In spite of lower levels of injury and longer rehabilitation stays, the current motor functioning based on the FIM was at about the same level in the two countries.

Given the comparable motor ability, it is not surprising that the two samples are very similar in terms of Physical Independence measured by the CHART, if mean scores are considered. However, the percentage who receive the maximum score of 100 (indicating zero hours of help with medical and selfcare) is much lower for the Turkish subjects (Table 3 ). There is a mean score difference for Mobility, with Turkish respondents reporting a somewhat lower level of independent mobility. This difference is more pronounced when the cap on the Mobility maximum score is removed, and even more marked if the percentage reporting complete lack of Mobility handicaps is considered.

The USA - Turkey difference in Occupation is of the same magnitude as that for Mobility, but not statistically significant. The percentage of subjects without any handicap in this respect is also very similar. If the cap on the maximum score is removed, the difference in favor of US respondents becomes larger, reaching statistical significance. It is of interest to note that most of the difference is due to the US respondents spending more time in work and in active recreation. There is no difference in Social Integration scores, but again there are significant discrepancies in the component items. US subjects report more contacts with business associates. Turkish subjects report more contacts with friends as well as living with a larger number of people in the same household. 
Table 2 Demographic and injury information

\begin{tabular}{|c|c|c|c|c|c|c|}
\hline \multirow[b]{2}{*}{ Variable } & \multicolumn{2}{|c|}{$U S A$} & \multicolumn{2}{|c|}{ Turkey } & \multicolumn{2}{|c|}{$\begin{array}{l}\text { ANOVA or } \\
\text { chi-square }\end{array}$} \\
\hline & Mean or $\%$ & $\mathrm{SD}$ & Mean or $\%$ & $\mathrm{SD}$ & $\mathrm{F}$ or $\chi^{2}$ & $\mathrm{P}$ \\
\hline \multicolumn{7}{|l|}{ Sex } \\
\hline Male & $81 \%$ & & $44 \%$ & & 14.4 & $<0.000$ \\
\hline Female & $19 \%$ & & $56 \%$ & & & \\
\hline \multicolumn{7}{|l|}{ Completeness of injury } \\
\hline Complete & $50 \%$ & & $52 \%$ & & 0.1 & ns \\
\hline Incomplete & $50 \%$ & & $48 \%$ & & & \\
\hline \multicolumn{7}{|l|}{ Level of injury } \\
\hline Cervical & $54 \%$ & & $11 \%$ & & 52.5 & $<0.000$ \\
\hline High thoracic (T1-T6) & $15 \%$ & & $6 \%$ & & & \\
\hline Low thoracic (T7-T12) & $23 \%$ & & $44 \%$ & & & \\
\hline Lumbar or sacral & $9 \%$ & & $39 \%$ & & & \\
\hline Days in rehabilitation & 77 & 33 & 137 & 44 & 114.4 & $<0.000$ \\
\hline Years since injury & 16 & 8 & 3 & 1 & 180.0 & $<0.000$ \\
\hline FIM motor score & 66 & 25 & 63 & 18 & 0.5 & ns \\
\hline Cases & 130 & & 66 & & & \\
\hline
\end{tabular}

Table 3 Social participation: CHART-SF item, subscale and total scale scores

\begin{tabular}{|c|c|c|c|c|c|c|}
\hline \multirow[b]{2}{*}{ Item, subscale or total } & \multicolumn{2}{|c|}{$U S A$} & \multicolumn{2}{|c|}{ Turkey } & \multicolumn{2}{|c|}{$\begin{array}{l}\text { ANOVA or } \\
\text { chi-square }\end{array}$} \\
\hline & Mean or $\%$ & $\mathrm{SD}$ & Mean or $\%$ & $\mathrm{SD}$ & $\mathrm{F}$ or $\chi^{2}$ & $\mathrm{P}$ \\
\hline Physical Independence & 93 & 16 & 90 & 12 & 1.0 & ns \\
\hline$\%$ with score of 100 & $58 \%$ & & $17 \%$ & & 30.5 & $<0.001$ \\
\hline Mobility-capped at 100 & 81 & 25 & 74 & 21 & 4.1 & $<0.05$ \\
\hline$\%$ with score of 100 & $45 \%$ & & $14 \%$ & & 18.9 & $<0.001$ \\
\hline Mobility-uncapped & 88 & 30 & 75 & 23 & 9.4 & $<0.01$ \\
\hline Occupation-capped at 100 & 72 & 33 & 65 & 37 & 1.7 & ns \\
\hline$\%$ with score of 100 & $47 \%$ & & $41 \%$ & & 0.6 & ns \\
\hline Occupation-uncapped & 101 & 68 & 76 & 50 & 7.2 & $<0.01$ \\
\hline Hours work & 16 & 24 & 9 & 15 & 5.0 & $<0.05$ \\
\hline Hours in class & 1 & 6 & 2 & 7 & 1.6 & ns \\
\hline Hours homemaking & 12 & 14 & 10 & 12 & 1.1 & ns \\
\hline Hours home maintenance & 3 & 7 & 3 & 4 & 0.0 & ns \\
\hline Hours recreation & 16 & 13 & 13 & 8 & 4.4 & $<0.05$ \\
\hline Soc. Integration-capped at 100 & 87 & 25 & 87 & 18 & 0.0 & ns \\
\hline$\%$ with score of 100 & $71 \%$ & & $55 \%$ & & 5.4 & $<0.05$ \\
\hline Soc. Integration-uncapped & 111 & 42 & 116 & 45 & 0.5 & ns \\
\hline Business contacts & 6 & 4 & 2 & 3 & 68.7 & $<0.000$ \\
\hline Friends & 4 & 2 & 6 & 3 & 44.9 & $<0.000$ \\
\hline People live with & 1 & 1 & 4 & 3 & 90.1 & $<0.000$ \\
\hline Married (\% yes) & 59 & & 55 & & & ns \\
\hline Economic Self-sufficiency & 53 & 44 & 39 & 28 & $\mathrm{a}$ & \\
\hline Cognitive Independence & 97 & 13 & 100 & 0 & 2.7 & $\mathrm{~ns}$ \\
\hline Total-uncapped & 393 & 119 & 357 & 96 & 4.6 & $<0.05$ \\
\hline Cases & 130 & & 66 & & & \\
\hline
\end{tabular}

${ }^{\text {a }}$ Statistical testing misleading; see Methods 
The perceived environmental barriers and problems that may underlie the social participation differences are summarized in Table 4. Availability of transportation was less of a problem to US subjects, as was expected. As anticipated, there also was no difference in barriers posed by nature. Contrary to expectations, US subjects reported more barriers resulting from 'other environmental aspects'. While Turkish individuals with SCI more often called lack of availability of health care a barrier, as hypothesized, the expected differences with respect to availability of information did not materialize. US subjects more often noted a lack of availability of help in the home, which was expected. Among those who considered lack of help in work and/or school relevant, Turkish subjects more often reported encountering this problem, or reported the absence of assistance as more problematic. However, if we assume that all other subjects had no barriers in this regard (score of 0 ), the country difference disappeared. That was not the case for attitudinal barriers in work or school: even after adjustment, higher barriers were typical of the Turkish sample's experience. Attitudes at home were very similar in the two societies. Turkish subjects did not report significantly more prejudice or discrimination, despite more barriers due to government and business policies.
On two of five CHIEF subscales (Physical/structural and Attitudes/support) there was no difference between the two countries, but on the remaining three the differences were statistically and substantially significant. The same was true for the CHIEF total score, whatever way it was calculated.

Reports of barriers solicited by the CHIEF are implicitly scaled in terms of the respondent's abilities (see Discussion). As a result, the level and completeness of injury, and the degree of motor ability are expected to influence CHIEF scores. The same is true for gender and age: as major determinants of social roles and personal expectations or desires, these two likely affect the report of barriers. Since there were sizeable inter-country differences in injury levels, gender and age, country differences in CHIEF scores may reflect demographic differences as well as discrepancies in absolute societal and natural conditions. The information in Table 5 indicates that even after controlling for gender, age and motor ability, significant country-level differences remain. These are either 'straight' discrepancies, or the interactive effect of country and the other characteristics. Interactions suggest that the effect of gender and motor ability on reports of barriers differs between Turkey and the USA. The table entries are eta-squared values, indicating the per cent of variance explained by the

Table 4 Perceptions of environmental barriers: CHIEF-SF items, subscales and total scores

\begin{tabular}{|c|c|c|c|c|c|c|}
\hline \multirow[b]{2}{*}{ Item, subscale or total } & \multicolumn{2}{|c|}{$U S A$} & \multicolumn{2}{|c|}{ Turkey } & \multicolumn{2}{|c|}{$A N O V A$} \\
\hline & Mean & SD & Mean & SD & $\mathrm{F}$ & $\mathrm{P}$ \\
\hline Transportation availability & 0.9 & 1.7 & 6.3 & 3.2 & 239.1 & $<0.000$ \\
\hline Natural environment & 1.2 & 1.7 & 1.5 & 2.4 & 0.4 & ns \\
\hline Surroundings - other & 0.5 & 1.2 & 0.0 & 0.2 & 8.6 & $<0.01$ \\
\hline Information availability & 0.5 & 1.4 & 0.6 & 0.7 & 0.6 & ns \\
\hline Health care availability & 1.0 & 2.2 & 2.5 & 2.2 & 23.8 & $<0.000$ \\
\hline Home help & 0.7 & 1.6 & 0.2 & 1.1 & 4.0 & $<0.05$ \\
\hline Work/school help ${ }^{a}$ & 0.3 & 0.9 & 1.1 & 2.8 & 3.9 & ns \\
\hline Work/school help ${ }^{b}$ & 0.1 & 0.6 & 0.1 & 0.2 & 0.6 & ns \\
\hline Home attitudes & 0.4 & 1.0 & 0.4 & 1.1 & 0.2 & ns \\
\hline Work/school attitudes ${ }^{\mathrm{a}}$ & 0.2 & 0.5 & 5.0 & 3.6 & 88.0 & $<0.000$ \\
\hline Work/school attitudes ${ }^{b}$ & 0.1 & 0.3 & 0.6 & 1.4 & 12.3 & $<0.01$ \\
\hline Discrimination & 0.6 & 1.7 & 0.7 & 1.0 & 0.1 & ns \\
\hline Business policies & 0.8 & 1.8 & 6.4 & 2.5 & 309.0 & $<0.000$ \\
\hline Government policies & 1.0 & 2.4 & 6.5 & 2.8 & 208.5 & $<0.000$ \\
\hline Policies & 0.9 & 1.8 & 6.5 & 2.3 & 330.4 & $<0.000$ \\
\hline Physical/structural & 0.8 & 1.0 & 0.7 & 1.2 & 0.3 & ns \\
\hline Work/school ${ }^{\mathrm{a}}$ & 0.2 & 0.6 & 3.1 & 2.7 & 52.9 & $<0.000$ \\
\hline Work/school ${ }^{\mathrm{b}}$ & 0.1 & 0.4 & 0.3 & 0.7 & 6.3 & $<0.05$ \\
\hline Attitudes/support & 0.5 & 1.1 & 0.5 & 0.8 & 0.1 & ns \\
\hline Services/assistance & 0.7 & 1.2 & 2.4 & 1.2 & 92.2 & $<0.000$ \\
\hline Total score ${ }^{\mathrm{a}}$ & 0.7 & 0.7 & 2.1 & 1.3 & 38.4 & $<0.000$ \\
\hline Total score ${ }^{b}$ & 0.7 & 0.8 & 1.7 & 0.6 & 209.8 & $<0.000$ \\
\hline Cases & 121 & & 66 & & & \\
\hline
\end{tabular}

${ }^{\mathrm{a} C a s e s}$ is 51 for Colorado, 26 for Turkey. ${ }^{\mathrm{b}} \mathrm{N} / \mathrm{A}$ coded as 'no barriers' (score 0) 
independent variable; in all instances the differences between Turkey and the USA in the 'country' column are in the same direction as shown in Tables 3 and 4. Many of the differences between the two countries in reported barriers remain even after controlling for some major determinants, although differences may be attenuated. Of the demographic and injury variables, only gender and motor ability, as quantified by the FIM, have an effect, by themselves and interacting with country. Especially conspicuous is the strong effect of motor ability on reports of physical/structural barriers. As could be expected, motor ability plays a minor role, if any, with respect to all other barriers.

Finally, participation differences between the two countries were hypothesized to be reduced by controlling for motor ability and demographic variables such as gender, and even more reduced after statistical controls for 'barriers' are introduced. Table 6 provides the relevant data; again, the table entries are etasquared values. The major effect of introducing motor ability and demographic variables is a reduction of country differences in Occupation such that the difference becomes almost non-significant. The FIM score plays the largest role here; gender and time since injury have no effects by themselves or in interaction. Introducing reported barriers as an explanation for participation differences appears to have limited effect; only for Social integration does the CHIEF score explain a significant degree of difference, both by itself and through its interactive effect with country. For the other three CHART subscores, introduction of the CHIEF score appears to have limited effect, indicating that participation differences between the societies are not accounted for by barriers and resources after controlling for other factors. Thus, support for our third hypothesis is minimal.

\section{Discussion}

As expected, this study found significant differences between individuals with SCI in Turkey and the USA in reports of barriers that interfere with their day-today life. Especially notable barriers included those created by or experienced in government and business

Table 5 Differences in perceptions of environmental barriers by country, gender, age, motor ability and time since injury

\begin{tabular}{|c|c|c|c|c|c|c|c|c|c|c|}
\hline CHIEF subscale and total & $R^{2}$ & $\begin{array}{c}\text { Country } \\
\text { A }\end{array}$ & $\begin{array}{c}\text { Gender } \\
\text { B }\end{array}$ & $\underset{\mathrm{C}}{\mathrm{Age}}$ & $\begin{array}{c}F I M \\
\text { D }\end{array}$ & $\begin{array}{c}\text { Time since } \\
\text { injury } \\
\mathrm{E}\end{array}$ & $A * B$ & $\begin{array}{r}\text { Intera } \\
\mathrm{A}^{*} \mathrm{C}\end{array}$ & $\begin{array}{l}\text { effects } \\
\mathrm{A}^{*} \mathrm{D}\end{array}$ & $A * E$ \\
\hline Policies & 0.67 & $0.06 * *$ & 0.01 & 0.00 & $0.02 *$ & 0.01 & $0.02 *$ & 0.00 & 0.00 & 0.01 \\
\hline Physical/structural & 0.33 & $0.05 * *$ & 0.02 & 0.01 & $0.22 * * *$ & 0.00 & 0.01 & 0.01 & $0.20 * * *$ & 0.01 \\
\hline Work/school ${ }^{\mathrm{a}}$ & 0.25 & 0.03 & $0.06^{*}$ & $0.06^{*}$ & 0.03 & 0.00 & $0.06^{*}$ & 0.00 & 0.04 & 0.00 \\
\hline Work/school ${ }^{\text {b }}$ & 0.14 & 0.00 & $0.05^{* *}$ & 0.01 & 0.01 & 0.01 & $0.06^{* *}$ & 0.01 & 0.01 & 0.01 \\
\hline Attitudes/support & 0.04 & 0.00 & 0.00 & 0.00 & 0.01 & 0.00 & 0.01 & 0.01 & 0.00 & 0.00 \\
\hline Services/assistance & 0.43 & 0.00 & $0.02 *$ & 0.00 & $0.03 *$ & 0.00 & 0.00 & 0.02 & 0.01 & 0.00 \\
\hline Total $^{\mathrm{a}}$ & 0.60 & $0.06^{* *}$ & 0.01 & 0.00 & $0.09 * * *$ & 0.00 & 0.00 & 0.00 & $0.03^{*}$ & 0.00 \\
\hline Total $^{\mathrm{b}}$ & 0.65 & $0.08 *$ & $0.06^{*}$ & 0.00 & $0.07 *$ & $0.14 * *$ & 0.04 & 0.02 & $0.06^{*}$ & $0.11^{* *}$ \\
\hline
\end{tabular}

${ }^{\mathrm{a}}$ Cases is 51 for Colorado, 26 for Turkey. ${ }^{\mathrm{b}} \mathrm{N} / \mathrm{A}$ coded as 'no barriers' (scored 0 ). ${ }^{*} P<0.05 ; * * P<0.01 ; * * * P<0.001$

Table 6 Differences in social participation by country, gender, time since injury, motor ability and perceptions of environmental barriers

\begin{tabular}{|c|c|c|c|c|c|c|c|c|c|c|c|}
\hline \multirow[t]{2}{*}{$\begin{array}{l}\text { CHART } \\
\text { subscale } \\
\text { and total }^{\mathrm{b}}\end{array}$} & \multirow[t]{2}{*}{$C H I E F^{\mathrm{a}}$} & \multirow[t]{2}{*}{$R^{2}$} & \multirow{2}{*}{$\begin{array}{c}\text { Country } \\
\mathrm{A}\end{array}$} & \multirow{2}{*}{$\begin{array}{c}\text { Gender } \\
\text { B }\end{array}$} & \multirow{2}{*}{$\begin{array}{l}\text { Time } \\
\text { since } \\
\text { injury } \\
\mathrm{C}\end{array}$} & \multirow{2}{*}{$\begin{array}{c}F I M \\
\text { D }\end{array}$} & \multirow{2}{*}{$\begin{array}{c}\text { CHIEF } \\
\text { total } \\
\text { score } \\
\mathrm{E}\end{array}$} & \multicolumn{4}{|c|}{ Interactive effects } \\
\hline & & & & & & & & $A * B$ & $\mathrm{~A} * \mathrm{C}$ & $\mathrm{A}^{*} \mathrm{D}$ & $\mathrm{A}^{*} \mathrm{E}$ \\
\hline \multirow{2}{*}{ Phys. Indep. } & without & 0.45 & $0.02 *$ & 0.00 & 0.00 & $0.39 * * *$ & NA & 0.00 & 0.00 & $0.04 * *$ & NA \\
\hline & with & 0.49 & 0.02 & 0.00 & 0.00 & $0.39 * * *$ & 0.00 & 0.00 & 0.00 & $0.05^{* *}$ & 0.00 \\
\hline \multirow[t]{2}{*}{ Mobility } & without & 0.23 & 0.04 & 0.01 & 0.00 & $0.17 * * *$ & NA & 0.00 & 0.00 & $0.04 * *$ & NA \\
\hline & with & 0.26 & $0.01 * *$ & 0.01 & 0.00 & $0.13^{* * *}$ & 0.01 & 0.00 & 0.00 & $0.02 *$ & 0.00 \\
\hline \multirow[t]{2}{*}{ Occupation } & without & 0.18 & 0.02 & 0.00 & 0.00 & $0.12 * * *$ & NA & 0.00 & 0.00 & $0.02 *$ & NA \\
\hline & with & 0.20 & 0.00 & 0.00 & 0.00 & $0.19^{* * *}$ & 0.01 & 0.00 & 0.00 & 0.01 & 0.01 \\
\hline \multirow[t]{2}{*}{ Soc. Integr. } & without & 0.06 & 0.01 & 0.01 & 0.01 & $0.04 *$ & NA & 0.00 & 0.01 & 0.02 & NA \\
\hline & with & 0.13 & 0.01 & 0.02 & 0.01 & 0.00 & $0.06^{* *}$ & 0.00 & 0.01 & 0.00 & $0.06^{* *}$ \\
\hline \multirow[t]{2}{*}{ Total } & without & 0.25 & $0.04 * *$ & 0.00 & 0.01 & $0.21 * * *$ & NA & 0.00 & 0.00 & $0.05^{* *}$ & NA \\
\hline & with & 0.28 & 0.00 & 0.00 & 0.01 & $0.15^{* * *}$ & 0.01 & 0.00 & 0.01 & 0.02 & $0.03 *$ \\
\hline
\end{tabular}

${ }^{\mathrm{a}} \mathrm{N} / \mathrm{A}$ coded as 'no barriers' (score 0 ). ${ }^{\mathrm{b}}$ Uncapped version. $* P<0.05 ; * * P<0.01 ; * * * P<0.001$ 
policies, work and school, and services and assistance outside the home. These differences by and large persisted after controlling for factors such as gender and degree of disability that can be expected to influence reports of barriers. The zero-order country differences were often explained in part by the interaction of country and the other factors. We also found the expected differences in social participation, with US subjects describing more active lives. However, the significant social participation differences between the two societies did not appear to be affected by environmental barriers and resources, but mostly by impairment and other individual characteristics. Social integration was a partial exception to this.

These findings could be taken as a lack of support for models that specify that the environment is a part of the disablement creation process. However, there are alternate explanations. Differences between the two samples in level of injury and its consequence, motor ability, may not have been fully removed by the statistical adjustments in the analyses. This research may not adequately measure the extent of injury and social participation and environmental barriers. Lastly, the relatively small sample size may have played a role; certainly, we did not adjust for multiple statistical tests, and the experiment-wide error allows this study to be designated only as a pilot.

This study brought to the fore a number of conceptual and methodological problems of research on social participation and how it is affected by barriers and supports. Some of these problems are unique to cross-cultural research, others are applicable to all investigations.

\section{The relationship between reports of barriers and participation level}

We may have been erroneous in our conceptualization of the relationships between ability, participation, and actual and reported barriers. In a sense, perceived (if not actual) barriers are the inverse of ability and aspirations. One would expect that all other things (such as life plans and actual barriers) being equal, reports of barriers would increase in direct proportion to the level of impairment and motor, cognitive or emotional disability. For instance, those who have perfect motor ability (the 'temporarily able-bodied') will report no barriers, and those with the highest level of disability (for instance, someone with $\mathrm{C} 2$ complete tetraplegia) will report maximum levels of physical/ structural barriers. If there is such a perfect correlation between the two, reports of barriers cannot explain additional variance in social participation once motor ability has been introduced as a predictor, and motor ability cannot increase variance explained once barriers have been put into the prediction equation. We know that this is an oversimplification of the situation, because there is no simple linear relationship between motor ability (or other aspects of disability) and barriers. For instance, discrimination (if present) is likely to be triggered by the presence of a wheelchair, and differences within the wheelchair users group are irrelevant. However, if there is a negative relationship between ability level and perceived barriers, simultaneous use of motor ability and reported barriers to predict social participation may need to be abandoned. In Table 5, the strongest relationship is between motor ability and report of structural/physical barriers, suggesting that this reasoning has at least some value to it.

Another assumption we made is that there is a negative relationship between social participation and reported barriers: persons with higher experience of barriers describe lower social participation levels, because it is the barriers out there in nature and society that keep them from more fully participating in community and society. However, the situation may be different: it may be the people with a more active professional and social life who report the most frequent and most severe environmental problems, because only they have an opportunity to be affected by barriers and lack of resources. In a Colorado survey of people with all types of disabilities, a complex relationship was found between perceived environmental barriers and social participation. ${ }^{20}$ Some domains of participation were negatively associated with specific aspects of the environment, indicating that barriers might reduce participation. On the other hand, some domains of participation (particularly occupation) were positively associated with environmental barriers, indicating that full social participation exposed people with disabilities to greater barriers. This observation has been made previously. ${ }^{21}$

Both of these issues are open to empirical verification. Researchers can collect information on objectively existing barriers in the environment of people with SCI, their reports of barriers, their level of disability, and the nature and extent of participation. Analysis would focus on variation in participation and in reports of barriers between persons with differing levels of disability, living in environments ranging for low to high in barriers. If within each disability levelbarrier level combination, participation reports and barrier reports co-vary, that would be proof of the strong relationship between reports of barriers and motor ability. A longitudinal study would be the best to evaluate the relationship between participation and report of barriers. We know that after completing rehabilitation, newly injured persons with SCI increase levels of participation over the first few years after return to the community. If their reports of barriers were to increase alongside reports of expanded community activities, that would be evidence of the primacy of participation.

\section{Translation}

The adequacy of translations between (American) English and the language of other countries (Turkish, in this instance) with which comparisons are to be 
made may cause problems. It would appear that translating is a fairly straightforward procedure; however, over 50 years of experience in cross-cultural research in the social sciences has indicated that there are many traps for unwary investigators to fall in. Even if we assume that the basic concept of community participation is applicable to Turkish society, and that the significant indicators are the same as those selected for the USA, we cannot always be certain that exactly the same information is collected. For instance, the CHART occupation component makes a distinction between work and recreation. Are these concepts and the distinctions between them experienced the same way in the two countries? Current experience in translating quality of life and similar instruments between languages, and development of new instruments in multiple languages simultaneously ${ }^{22,23}$ has indicated the degree of difficulty in equating terms at the linguistic and functional level.

\section{Handling 'non-applicable' reports for barriers}

A major problem we encountered with respect to scoring of the CHIEF, for both US and Turkish respondents, was the 'not applicable' answer to questions on barriers encountered in school or at work. If we ask a 70 year old about problems at work, an 'NA' answer makes sense. But what about 30 year olds? Should we assume they are independently wealthy, and do not need to work? Or is the truth that they tried to (return to) work, years ago, and experienced barriers to such a degree that they gave up? Or maybe that knowing the barriers, they never even tried? In that case, it is understandable that they would report 'not applicable to their (current) life'. But from the perspective of someone interested in policy issues, they should be counted in the 'barriers' column. If one takes these individuals at their word, and codes them 'NA', an underestimate of barriers to work and school is likely, because those who are working or attending school may be encountering some barriers, but not so severe as to make attendance altogether impossible. And an estimation of barriers will be based on their averaged reports. On the other hand, if one codes people who have in the past encountered insurmountable barriers to employment as 'not reporting barriers', an undercount of barriers also results, because this group brings down the overall average.

The correct way to handle problems like this may be to give individuals who ought to be working the maximum barrier score - because environments that make desired or normative activities completely impossible deserve such a designation. The problem with this approach is that without further questioning, we don't know who would or should be engaging in the activities in question, if it were not for the barriers or lack of resources. Assigning 'maximum barrier' points may result in significant overestimates of impediments to social functioning; this is the reason we did not implement this alternative.
The only solution to this problem would be to ask two kinds of questions. First we should explicitly ask people what level and types of functioning they would like to enjoy. Then we should ask whether there are any environmental barriers that keep them from doing those things at all, or with the quality, quantity or ease that they would like, or that is normal for nondisabled persons. The CHIEF questions implicitly ask respondents to consider experience of barriers in terms of their goals for participation rather than their achieved participation. However, it is likely that many will not report as barriers the worst ones - those that make some aspect of social participation completely impossible. It should be noted that even studies that investigate the effect of environmental barriers as measured objectively (rather than in terms of subjectively experienced problems) may have to deal with this problem. Environments that completely eliminate participation are likely to be ignored, unless the investigators ask potential users explicitly to report not just what they do, but also the locations and situations they avoid because of impossibly high barriers.

\section{Quantifying social participation}

The CHART was designed to distinguish between the level of social participation experienced by people with a disability and that of the typical non-disabled person. ${ }^{6}$ The scoring algorithm was developed such that every non-disabled person is likely to score 100 or more points, while many persons with a disability score less. Because the interest of the developers was in differentiating within the category of persons with a disability, the modal or minimal level of functioning of nondisabled persons was set as the norm. Capping the maximum score on every subscale to 100 makes sense, because there was no interest in differentiating within the category of 'normal'. However, when the CHART is used with a group of individuals who have limited impairments or who live in an 'enriched' environment which poses some degree of barriers, many will score the maximum on the majority of if not all subscales. Furthermore, when the concept of 'normal' differs from place to place, as it may in this study, those with scores below 100 in the USA, for example, might have scored 100 in Turkey, had CHART been developed in Turkey.

The scoring cap creates statistical analysis difficulties too. The 100 maximum will create a distribution that is extremely skewed, causing problems with all statistical analysis techniques that assume approximately normal distributions - the parametric tests. However, the alternative, the non-parametric tests as implemented by major statistical software packages, are limited in the number of variables that can be analyzed simultaneously, thus restricting our ability to understand the concurrent impact of many factors on functioning. Because the focus in the present analysis was on differences between two groups of persons with 
SCI, one in a limiting environment (Turkey) and one in a comparatively rich milieu (USA), 'uncapping; CHART subscores made sense. However, in Table 3 information on capped CHART scores was provided because that gives some indication of how individuals with a SCI in both countries fare compared to US non-disabled peers.

Dijkers et $a l^{4}$ discuss the difficult issue of defining and measuring 'abnormal social functioning', make several suggestions for improved measurement, and evaluate some of the more prominent measures currently available. All of them have shortcomings; however, we would suggest that they are adequate for use in a sample that is fairly homogeneous in terms of age, marital status and other cultural and social factors that affect social roles, and heterogeneous in terms of impairment. We certainly have a better handle on the measurement of participation than of environmental supports and barriers, and progress in research on the impact of environmental factors on disablement depends on advancement in this area.

\section{The measurement of motor ability}

As was noted above, the mean FIM score for the Turkish sample was the same as for the US sample, in spite of the fact that the latter typically had a higher level of injury. The explanation may not be translation problems, but the nature of the FIM. Though we have described it as a measure of motor ability, that is only true if one reports what a person can do, rather than what $\mathrm{s} /$ he routinely does. The FIM, especially in its self-report version, records actual performance. Actual performance cannot be higher than ability, but it can be lower - a lot lower. The fact that the actual performance of the Turkish subjects is so much lower than what every SCI specialist knows to be their potential, likely is due to the fact that many of these individuals always have some other person to do things for them. As was indicated in Table 1, in Turkish culture the person with a disability is treated 'like a baby' and taken care of. Besides, inside the typical Turkish house the bathroom and kitchen are inaccessible because modifications are not covered by insurance. Hence, culture and the availability of assistance push more help on the person than is truly needed, and lack of access within the residence adds to this. Thus, environment impacts ADL performance as much as it does social participation. However, for predicting social participation, potential (ie motor ability) likely is a better measure than actual performance.

Future research in this area may do better to use an instrument that quantifies 'can do' (rather than 'does do'), especially if there are large interindividual differences between potential and actual motor performance. ${ }^{24}$ The FIM can be used for this purpose, after questions have been modified, from 'How do you typically do ...' to 'If you had to, how much could you do of ...' Collecting both types of information, and inquiring as to the reasons for discrepancies (convenience, lack of time, conserving energy, overprotective family, etc. ${ }^{25}$ ) would provide useful information as to the effect of environment on activity and activity limitations. The World Health Organization model of disablement specifies that environmental factors affect the relationship between impairments and activity limitations, just as (different) environmental factors affect the relationship between the latter and participation restrictions. Both of these subjects deserve further research.

\section{Acknowledgements}

Thanks to Reha Yavuzer MD for his work on the translation of instruments. This work was supported in part by grants from the National Institute on Disability and Rehabilitation Research (NIDRR), Office of Special Education Services, US Department of Education to Mount Sinai School of Medicine (H133N000027) and Craig Hospital (H133N00001), and from the Centers for Disease Control and Prevention (CDC) to Craig Hospital (RO4/CCR814132 and R04/CCR818819). The conclusions of this paper are not necessarily endorsed by either NIDRR or CDC.

\section{References}

1 World Health Organization. ICIDH-2: International Classification of Functioning, Disability and Health. Final draft, full version. Geneva: World Health Organization, 2001.

2 Fougeyrollas P et al. Revision of the Quebec Classification: Handicap Creation Process. International Network on the Handicap Creation Process, Quebec, Canada, 1997.

3 National Institute on Disability and Rehabilitation Research. Long-Range Plan for Fiscal Years 19992003. Federal Register, December 7, 1999 (Volume 64, Number 234), 68575-68614.

4 Dijkers MPJM, Whiteneck G, El-Jaroudi R. Measures of social outcomes in disability research. Arch Phys Med Rehabil 2000; 81 (Suppl 2): S63-S80.

5 Danford GS, Steinfeld E. Measuring the influences of physical environments on the behaviors of people with impairments. In: Danford GS, Steinfeld E (eds) Enabling environments: Measuring the impact of environment on disability and rehabilitation. New York, NY: Kluwer Academic/Plenum Publishers, 1999, pp 111-137.

6 Whiteneck G et al. Quantifying handicap: A new measure of long-term rehabilitation outcomes. Arch Phys Med Rehabil 1992; 73: 519-526.

7 Hall KM et al. The Craig Handicap Assessment and Reporting Technique (CHART): Metric properties and scoring. Top Spinal Cord Inj Rehabil 1998; 4: 16-30.

8 Cusick CP, Brooks CA, Whiteneck GG. The use of proxies in community integration research. Arch Phys Med Rehabil 2001; 82: 1018 - 1024.

9 Segal ME, Schall RR. Assessing handicap of stroke survivors. A validation study of the Craig Handicap Assessment and Reporting Technique. Am J Phys Med Rehabil 1995; 74: 276-286. 
10 Dijkers M. Correlates of life satisfaction among persons with spinal cord injury. Arch Phys Med Rehabil 1999; 80: $867-876$.

11 Whiteneck GG, Brooks CA, Melick D. The creation of the Craig Hospital Inventory of Environmental Factors (CHIEF). Unpublished manuscript, Craig Hospital, Denver CO, 1999.

12 Hamilton BB et al. A uniform national data system for medical rehabilitation. In: Fuhrer M (ed). Rehabilitation outcomes: analysis and measurement Baltimore: Brookes Publishing, 1987, pp 137-147.

13 Whiteneck GG. A Functional Independence Measure trial in spinal cord injury model systems. Proc Am Spinal Inj Assoc 1988; 14: 48.

14 Ottenbacher KJ, Hsu Y, Granger CV, Fiedler RC. The reliability of functional independence measure: a quantitative review. Arch Phys Med Rehabil 1996; 77: 12261232.

15 Bracken $\mathrm{MB}$ et al. Administration of methylprednisolone for 24 or 48 hours or tirilazad mesylate for 48 hours in the treatment of acute spinal cord injury. Results of the Third National Acute Spinal Cord Injury Randomized Controlled Trial. National Acute Spinal Cord Injury Study. JAMA 1997; 277: 1597 - 1604 .

16 Linacre JM et al. The structure and stability of the Functional Independence Measure. Arch Phys Med Rehabil 1994; 75: $127-132$.

17 Hall KM et al. Characteristics of the Functional Independence Measure in traumatic spinal cord injury. Arch Phys Med Rehabil 1999; 80: 1471-1476.
18 Dijkers MPJM, Yavuzer G. Short versions of the telephone Motor Functional Independence Measure for use with persons with spinal cord injury. Arch Phys Med Rehabil 1999; 80: 1477 - 1484.

19 Yavuzer G, Süldür N, Küçükdeveci A, Elhan A. The value of FIM and MBI in assessment and follow-up of neurorehabilitation patients. $J$ Rheumatol Med Rehabil 2000; 11: $26-31$.

20 Whiteneck G, Brooks CA, Mellick D, Harrison-Felix C. The relationship among disability, participation, and environmental factors. Presentation at the American Public Health Association Meeting, Boston, 2000.

21 Conroy L, McKenna K. Vocational outcome following spinal cord injury. Spinal Cord 1999; 37: 624-633.

22 Skevington SM, Tucker C. Designing response scales for cross-cultural use in health care: data from the development of the UK WHOQOL. Br J Med Psychol 1999; 72: $51-61$.

23 Orley J, Saxena S, Herrman H. Quality of life and mental illness. Reflections from the perspective of the WHOQOL. Br J Psychiatry 1998; 172: $291-293$.

24 Young NL et al. The context of measuring disability: does it matter whether capability or performance is measured? J Clin Epidemiol 1996; 49: 1097-1101.

25 Williams GH. Disablement and the social context of daily activity. Int Disabil Stud 1987; 9: $97-102$. 